\title{
How Much Polish Consumers Know about Alternative Fuel Vehicles? Impact of Knowledge on the Willingness to Buy
}

\author{
Anna Kowalska-Pyzalska ${ }^{1, *} \mathbb{*}$, Marek Kott ${ }^{2}\left(\mathbb{D}\right.$ and Joanna Kott $^{1}(\mathbb{D}$ \\ 1 Department of Operations Research and Business Intelligence, Faculty of Computer Science and Management, \\ Wrocław University of Science and Technology, 50-370 Wrocław, Poland; joanna.kott@pwr.edu.pl \\ 2 Department of Electrical Power Engineering, Faculty of Electrical Engineering, Wrocław University of Science \\ and Technology, 50-370 Wrocław, Poland; marek.kott@pwr.edu.pl \\ * Correspondence: anna.kowalska-pyzalska@pwr.edu.pl
}

check for updates

Citation: Kowalska-Pyzalska, A.; Kott, M.; Kott, J. How Much Polish Consumers Know about Alternative Fuel Vehicles? Impact of Knowledge on the Willingness to Buy. Energies 2021, 14, 1438. https://doi.org/ 10.3390/en14051438

Academic Editor: Hrvoje Pandžić

Received: 18 January 2021

Accepted: 1 March 2021

Published: 5 March 2021

Publisher's Note: MDPI stays neutral with regard to jurisdictional claims in published maps and institutional affiliations.

Copyright: (c) 2021 by the authors. Licensee MDPI, Basel, Switzerland. This article is an open access article distributed under the terms and conditions of the Creative Commons Attribution (CC BY) license (https:// creativecommons.org/licenses/by/ $4.0 /)$.

\begin{abstract}
Limited consumer knowledge reduces the chances of the spread of alternative fuel vehicles (AFVs), and hence slows down AFV market spread. In our empirical survey conducted in the first quarter of 2020 among 1002 Poles planning to buy a car in the next 12 months or who have just bought one, we examine what socio-economic and attitudinal factors influence their willingness to buy an AFV. In particular, we are interested in exploring how AFV knowledge related to understanding of the differences between hybrid electric vehicles (HEVs), plug-in hybrid electric vehicles (PHEVs) and battery electric vehicles (BEVs), as well as brand recognition associate with the willingness to buy. To the best our knowledge, this is a unique study among consumers in Central and Eastern Europe, characterized by lower exposure to AFVs and lower purchasing power. Our results indicate that males with pro-environmental beliefs and behaviors who are interested in modern automotive technologies and have good AFV brand recognition are predominated to be willing to buy an AFV in the near future.
\end{abstract}

Keywords: knowledge; e-mobility; sustainable transport; electric vehicles; plug-in electric vehicles; hybrid electric vehicles; consumers; willingness to buy; telephone survey

\section{Introduction \\ 1.1. Background and Motivation}

Achieving the 2030 Sustainable Development Agenda requires the establishment of "sustainable transport systems, along with universal access to affordable, reliable, sustainable, and modern energy services, quality and resilient infrastructure, and other policies that increase productive capacities that would build strong economic foundations for all countries". Sustainable transport is necessary to enable the achievement of a variety of sustainable development goals (SDGs), both directly and indirectly in the following areas: energy efficiency, sustainable infrastructure, urban access, and fossil fuel subsidies, as well as agricultural productivity, air pollution, access to safe drinking water, sustainable cities, reduction of food loss, climate change adaptation, and climate change mitigation [1].

The transportation sector is responsible for a large share of greenhouse gas emissions (GHG). In the European Union, road transport alone accounts for $72.06 \%$ of total transport $\mathrm{CO}_{2}$, which is considered a cause of climate change [2]. Presently, emphasized by [2-4], the use of alternative fuels has become a pressing issue and a lot of effort has been given to develop alternative fuel vehicles (AFVs) including hybrid electric vehicles (HEVs), plug-in hybrid electric vehicles (PHEVs), and battery electric vehicles (BEVs), which would satisfy social, economic, and environmental needs and requirements. Without any doubt, the evaluation of AFVs should consider not only air pollution reduction and fuel efficiency, but also AFV sustainability [2,5]. AFVs are also perceived as a great chance for smart urban mobility where a combination of sustainability and innovation is required $[5,6]$. Furthermore, smart and sustainable urban mobility is an important part of a 
smart city, where innovation technology adopted in AFV may lead to lower emissions and greater comfort of living [5]. That is why governments around the world intend to adopt AFVs to build a sustainable transport system [3,7-10] and have set goals to accelerate BEV and PHEV adoption [5]. In order to achieve these goals, governments have introduced incentive policies, such as subsidies, tax exemptions, and transportation regulatory policy to promote smart electric mobility [11].

Despite technological and policy support, AFV market share remains limited globally [12]. Electric car deployment has been growing over the past ten years, with the global stock of electric passenger cars reaching 7.2 million in 2019, an increase of $40 \%$ from the previous year. Around $47 \%$ of electric cars on the road in 2019 were in China-a total of 3.38 million-compared to $45 \%$ in 2018 . With $90 \%$ of global electric car sales concentrated in China, Europe and the United States, this has affected global sales and overshadowed the notable 50\% sales increase in Europe in 2019 [13].

One of the most important barriers to AFV adoption may be a general lack of knowledge and awareness about AFV [3,14-17]. The literature review indicates that consumer awareness and knowledge towards AFV is still very limited, which has an influence on consumer interest, engagement and willingness to buy such a car [14,18-24]. This problem exists even in countries such as the United States, the United Kingdom or Canada, where the alternative transportation sector is more developed in comparison to Central and Eastern European (CEE) countries. For example, in the United States in some recent studies, less than half of consumers were able to name a particular PHEV brand and were aware of the incentives offered to buy a BEV $[4,25]$.

\subsection{The Actual State of the Car Market in Poland}

In Poland at the end of 2020, among 20.5 million passenger cars travelling on Polish roads, only 128,000 (around $0.6 \%$ ) could be classified as AFV. The vast majority of themover 109,000-belong to standard HEVs. According to the Polish Association of Automotive Industry, there are about 10,000 registered BEV and around $8800 \mathrm{PHEV}$. AFV are mainly (89\%) bought directly in car showrooms by companies (over 61\%) rather than private individual buyers representing households.

It should be noted that at the same time AFV sales are growing from year to year. In 2020, $9879 \mathrm{BEV}$ and PHEV vehicles were registered, which is $140 \%$ more than in 2019 [26,27]. This is caused, among others, by growing ecological awareness among potential buyers of new vehicles. According to the Transportation and Environment Report it is also fashionable to have an AFV [28].

The offer of electric vehicles in Poland is comparable to other European countries. There are over 80 models from various segments on the Polish market. Urban crossovers and SUVs are leading the way [29]. It happens, however, that the availability of some models is limited. The high interest in 2020 for urban electric vehicles (such as the Skoda CITIGOe IV, VW e up) meant that the car dealer stocks ran out quickly. As a result, the possibility of purchasing an urban electric vehicle was significantly reduced or had to be postponed to another year.

One of the biggest barriers to the development of AFV in Poland is the charging infrastructure. The number of public charging points is around 1300. This means that there are only 0.2 charging points per $100 \mathrm{~km}$ of roads, while in neighboring countries this indicator reaches values of 0.6 in the Czech Republic, 1.1 in Slovakia 1.1, and even 17.6 in Germany [30,31]. Legal regulations constitute another barrier to the development of e-mobility. There is still lack of state support for potential AFV buyers in the form of appropriate subsidies. A detailed analysis of the AFV market in Poland is presented in [29].

\subsection{Research Goals}

Our empirical research was conducted in the first quarter of 2020 on the sample of 1002 adult Poles. All our respondents were claiming to be willing to purchase a car 
in the next 12 months or have already bought one in the last six months. The study aimed to examine the Polish market, which is a good example of an automotive market in Central and Eastern Europe. In particular, it represents consumers with lower exposure and experience with AFVs, as well as limited purchasing power in comparison to the consumers in Western European countries or in the U.S., Canada, or Australia (where the AFV market is much more developed). The goal of the study was not only to explore and describe the level of consumer AFV knowledge in terms of their ability to recognize types of AFV (based on the type of the engine) and brand names, but also to investigate which socio-economic and attitudinal factors are associated with the willingness to buy an AFV. The choice of the factors included in the analysis was dictated by the literature review. To analyze the willingness to buy an AFV, we used ordinal logistic regression, as it allows observation of how the increase of the willingness to buy more electrified cars (i.e., BEV instead of $\mathrm{HEV}$ or conventional car) associates with consumer attributes such as gender, education, pro-environmental attitudes and behaviors or interest in modern automotive technologies.

Our paper also provides an up-to-date literature review in terms of the role of knowledge and awareness in AFV recognition. We believe that raising awareness and knowledge is the first step in consumer acceptance and AFV adoption in the automotive market. To the best of our knowledge, similar studies have been run in Canada, the UK and the U.S., but not in Central or Eastern Europe. We believe that it is interesting to investigate this part of the market, as according to the EU directives as well as the New Urban Agenda, the further development of sustainable urban mobility requires, among others, the deployment of AFV within private and public transportation. Our study sheds some light on factors relevant to AFV knowledge. Based on that, some policy recommendations, as well as marketing strategies, can be developed to increase consumer interest towards hybrid and electric vehicles.

The remainder of the paper is as follows. In Section 2 the role of knowledge and awareness in AFV recognition is presented and the research questions are formulated. Furthermore, in Section 3 the survey framework and data collected are shown, and in Section 4 the results are discussed. The last Section 5 provides some conclusions and policy recommendations.

\section{Literature Review: The Role of Socio-Economic and Attitudinal Factors in Willingness to Buy AFV}

Willingness to buy (WTB) is the behavioral intention of the customer to purchase a product or a service. WTB, dependent on the sort of good, may be influenced by price sensitivity, product quality, brand name, as well as a set of socio-economic and attitudinal factors, such as environmental beliefs, seeking for novelty, or perceived cost and benefit analysis [32-35]. Willingness to buy or willingness to change from conventional car to an alternative one measures one's readiness to adopt one of AFV [33,36].

The market report of the Starcount Observatory Platform [37] reveals that consumers' WTB of BEV is motivated mostly by ecological motivation (i.e., willingness to participate in climate protection), enthusiasm for new technologies or passion for driving and experiencing new cars and technical solutions, and finally the desire to optimize the spending on the car in such a way to get a fashionable product for a reasonable price.

Apart from that, WTB is limited by several barriers. Range anxiety and the cost of the car belong to the most significant concerns. The meta-analysis conducted by Deloitte in 2018 in different countries has shown that dependent of the market and culture of the consumers, the incentives and barriers vary. Driving range was highlighted as the top barrier for Germany, Belgium, UK, and China whereas Japan, USA and France indicated price (cost) as the most severe barrier to AFV adoption. For Italy, India and Korea, the lack of infrastructure was the highest barrier. Limited access to vehicle charging points was a problem as well. Home charging is still not available for many consumers, especially those living in urban areas. Charging time and battery safety were the next barriers for all markets. In more collective cultures, such as, for example, Chinese ones, the perceived 
social influence as well as individual environmental awareness may have a positive impact on the willingness to purchase BEV [37].

WTB is usually discussed together with the willingness to pay (WTP) that measures the maximum price of the good at which the consumer will buy the product $[36,38-41]$. WTP studies use either the contingent valuation method (CVM) $[36,42,43]$ or the choice experiment (CE) [22,44-46] to determine the influence of various factors on WTP. These factors refer to consumer sociodemographic variables, such as age, income or education, and to the product attributes such as price, range, or brand name. Both methods belong to the group of methods based on stated preferences, which ask actors explicitly how much respondents value the good [43].

Recent studies reveal that, especially in case of BEV, attributes such as range, price, acceleration, charging availability and recharging time mostly matter $[33,35,36]$. The study of Jensen et al. [47] shows that WTP increases also with knowledge and experience of usage of the AFV. Noel et al. [46] reveals that interest in BEV increases with choice of BEV models and general consumer awareness of air quality issues and environmental impact of transportation. The study of Ramos-Real et al. [36] shows that information on the basic properties of BEV and environmental concerns are key factors for willingness to exchange a conventional car for an electric one, while income level, mobility patterns, environmental concerns and attitude-to-tech of potential buyers were found to be important factors for their WTP.

The most important factors influencing consumer willingness to buy an AFV are discussed below.

\subsection{Status Quo of AFV Knowledge}

There is a great number of studies evaluating the importance of consumer awareness and knowledge in the context of both WTB and WTP. Even if most of the studies relates to BEV only $[18,35,36,45,48-53]$, some of them still focus of PHEV $[9,22,54-58]$ or compare and review a few types of AFVs together (e.g., HEV and BEV in [59] or HEV, PHEV and BEV in [60]). Some recent studies conducted in the United States revealed that less than half of American consumers can name a specific PHEV make and model, and even less than $35 \%$ of California households are aware of incentives offered for the purchase of BEV [14].

Overall, these studies show that general consumer awareness of AFVs is relatively low, and this includes lack of familiarity with the new technology, lack of knowledge of available incentives, models and their technical parameters, and misperception about the potential savings from lower fuel and maintenance costs [14]. Generally, most of the consumers misunderstand the basic characteristics of PHEV, and most of them are not aware of available incentives $[14,19,24]$. This lack of awareness and knowledge regarding available models and incentives has been found to be a primary barrier to AFVs widespread adoption $[4,14,21]$.

\subsection{The Role of Experience and Education}

There are several main sources of AFV knowledge, among which education and social campaigns, advertisement, test drives, and social influence (e.g., word-of-mouth between drivers and potential buyers) are the most important [14,56]. Generally, consumer interest in buying a AFV increases when they have exposure to them $[15,18,61]$.

Reiner et al. [62] in a paper examining e-mobility in Stuttgart in Germany, note that as people have more experience with driving a $\mathrm{BEV}$, they show more favorable attitudes towards e-mobility in general (see also $[25,63,64]$ ). The strong impact of the test drive on the BEV purchase has been also proved by [64] in their study among European countries in 2015.

\subsection{The Relation between AFV Knowledge and Willingness to Pay and Buy}

Individuals with greater familiarity and experience with BEVs are more likely to value them higher $[18,36]$. Given that there is a positive relationship between awareness 
and interest in purchasing, consumers with better knowledge of AFV are more willing to pay a premium for this technology [4]. Nevertheless, even well-informed consumers are sometimes unaware of the lifetime fuel savings that for example BEVs may offer [61]. A survey by Consumer Federation of America showed that there is correlation between BEV knowledge and positive attitudes towards the technology and between positive attitudes and a willingness to purchase them [21]. Therefore, the more knowledge about a given type of a vehicle, the more likely it is to be bought.

Literature review reveals that limited awareness, knowledge and interest among consumers towards an innovation leads to concerns regarding the acceptance of the same (see some examples from the energy market [65-68]). Customer concerns regarding AFV include high initial investment cost, unclear environmental impact in case of a battery and its storage, lack of sufficient charging stations and many others [20,29]. Such uncertainty regarding AFV may become a barrier to widespread adoption. As the literature review indicates, it may have its main source in the lack of understanding and familiarity with AFV [14,20,53].

Given the above findings, we propose the following hypothesis:

Hypothesis 1 (H1). Willingness to purchase AFV increases with AFV knowledge.

\subsection{Interest and Positive Attitudes towards New Technologies}

There are various possible motivations for the consumers to get interested in AFV. As emphasized in the work of Axsen et al. [69], for some consumers a battery electric vehicle will be a cutting-edge technology they want to enjoy, and for the others BEV represents a pro-environmental lifestyle and ecological values they support. Then, tech enthusiasts, so people who are excited by the latest developments in gadgets, computers and technology trends, are predominated to be interested in the purchase of BEV [37].

A clear and significant correlation between knowledge of AFV and positive attitudes towards this new technology has been found empirically in $[4,15,21,22]$. Next, it has been found that knowledge may have an indirect effect on the intention to buy AFV through the perceived attributes of these cars, see e.g., [33]. Based on these findings we suspect that consumers interested in the automotive industry in general and the novelties available in this market are those who should be more interested in purchase of such a car. Hence, we propose a following hypothesis:

Hypothesis 2 (H2). Interest in new technologies raises the willingness to buy AFV.

\subsection{Eco-Friendly Attitudes and Behaviors}

As mentioned in Section 1, BEVs are often perceived as a means of transport favorably reducing air pollution, i.e., producing fewer greenhouse gases compared to conventional vehicles (CV). However, still, the ecological nature of BEV is often criticized [70] . It is widely believed that the purchase of BEV does not affect the reduction of $\mathrm{CO}_{2}$ emissions, especially in countries such as, e.g., Poland, where most of the electricity is generated in power plants using fossil energy resources such as hard coal or lignite. However, according to report Transport and Environment in 2020 [28], even in Poland, the production and operation of $\mathrm{BEV}$ reduces $\mathrm{CO}_{2}$ emissions by $-29 \%$ compared to conventional vehicles, while the average reduction for the entire EU is $-63 \%$. Until now, car batteries were produced in a relatively small amount, and most of them still power electric cars. Used batteries are stored and disposed of in the pilot recovery projects [28].

The literature analysis indicates that BEV ownership and use is often perceived as a way to engage in pro-environmental actions [71]. Moreover, as revealed in [35,69], possession of BEV often represents one's pro-environmental values and beliefs. On the other hand, in the work of [14], there is no clear evidence that people who are pro-environmental are more willing to purchase an AFV. 
Even though the findings are ambiguous, we still want to check if those who care about environment protection, climate change, and perform at least the most basic proenvironmental behaviors such as waste segregation, turning off the lights, or limiting water usage, are more probable to be willing to purchase AFV.

Here we propose a following hypothesis:

Hypothesis 3 (H3). Eco-friendly attitudes and behaviors are associated with willingness to purchase AFV.

\subsection{The Role of Charging Stations}

Research conducted in 2015 in Canada showed that the size of the charging grid does not affect the desire to buy a BEV [22]. However, other research has shown a correlation between the number of charging grids, their location (distance from the workplace) and the interest in purchasing BEV $[25,72,73]$.

Hence, we propose a hypothesis:

Hypothesis 4 (H4). The advanced infrastructure and the easy access of the charging stations increases the willingness to buy an AFV.

\subsection{The Demographic Attributes in the Context of AFV Knowledge}

Many studies have revealed that socio-economic attributes of the consumers also matter in terms of their interest and willingness to buy an AFV. Studies examining consumer preferences in terms of their decisions to buy an AFV have revealed that this interest is higher among young, highly educated, environmentally conscious consumers $[32,44,69,74]$. Some studies also argue that males show more interest in BEV technology than women [32]. Other studies additionally indicate that environmentally concerned middle-aged households and those who are fully employed are more willing to adopt BEVs [44].

Within our study we want to verify the relationship between some socio-economic attributes and willingness to buy, and hence we propose the following hypotheses:

Hypothesis $\mathbf{5}$ (H5). Socio-economic variables such as age, gender or education are associated with willingness to buy AFV.

Hypothesis 6 (H6). Running a business increases the probability of willingness to buy AFV.

\section{Methods and Survey Design}

\subsection{Research Framework of WTB}

The empirical part of the survey was designed and used to identify and evaluate background information related to the consumer interest in AFVs, including household vehicle information, vehicle use and driving habits, AFV awareness and familiarity, home/work charging access, lifestyle, values and attitudes scale. In this step of the survey, we also collected some important demographic attributes (age, education, income, place of a living, household size, etc.). The survey was conducted within the CATI (Computer-Assisted Telephone Interviewing) method.

Figure 1 presents the research framework of consumer willingness to buy (WTB) of AFV. It consists of 6 variables with a potential influence on WTB. The choice of these variables was motivated by the literature review.

\subsection{Data Collection and the Sample}

The data were collected from January-February 2020 by a professional pooling agency through a telephone survey. Adult consumers willing or planning to buy a car in the coming 12 months or those who have already bought one in the last half a year were our target group. 
Although a survey was done on a dedicated panel data, still some screening questions were asked to ensure that our respondents belong to the target group. In total, 1002 responses were collected with a $2.5 \%$ response rate. Among the sample, $65.6 \%$ considered buying a car in the coming 12 months, and $34.4 \%$ had bought a car in the last half a year. The majority of the respondents was interested in second-hand cars, and only $27.8 \%$ considered the purchase of a new car. Such a tendency is very typical of the Polish automotive market. At the time of data collection, around $93 \%$ of respondents possessed at least one car, but only $1 \%$ owned an $\mathrm{AFV}$, whereas the rest had a combustion engine.

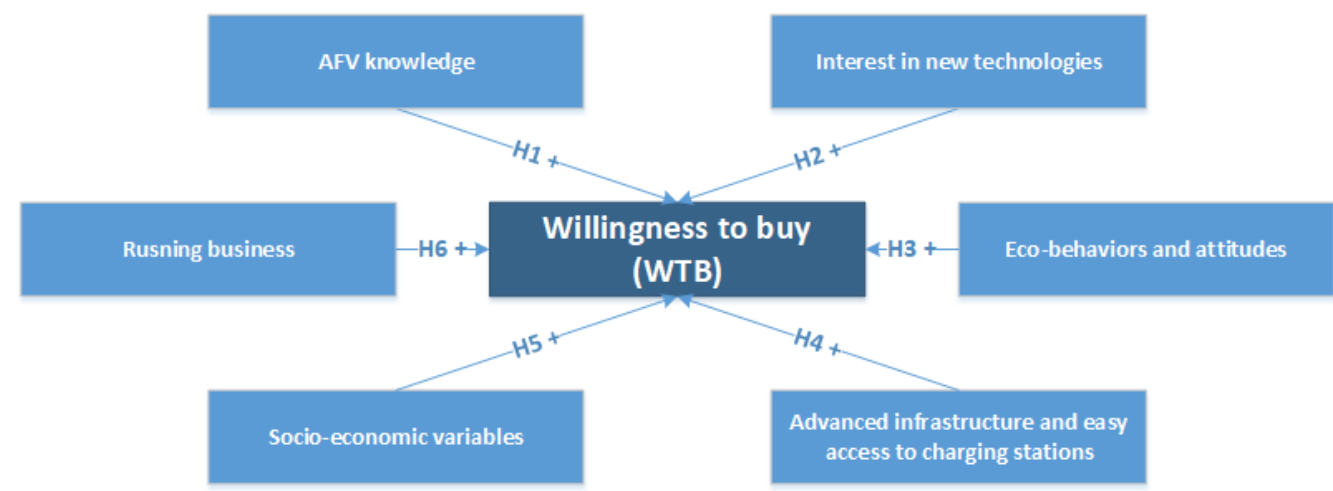

Figure 1. Research framework of the consumer willingness to buy (WTB) of AFV.

As the study had an exploratory character, and no demographic quotas were required, the sample represents Poles being interested in the purchase of a car; see Table 1.

The sample underrepresents people with a bad financial situation (who are not considering buying a car), while it excessively represents well-educated people with larger families, in which there are two drivers on average. Men were more interested in the survey, probably due to its scope and topic. On the other hand, our sample satisfactorily reflects the distribution of age and place of residence. In the end, among the respondents, $\mathrm{N} 1=804$ represented households, and N2 $=198$ were entrepreneurs, running their own small- or medium-sized businesses. The firms represented in the study were relatively young (8-9 years, on average), and small (on average 4 employees), representing all industries. The broader analysis of the point of view of the firms participating in the study towards the AFV is presented in [75].

To investigate the respondents' willingness to buy as well as the amount of money they would be willing to spend on a new car, we asked them a few questions, described precisely in Section 4.1. The answers to these questions revealed not only the level of respondent willingness to pay (divided into a purchase or a leasing), but also their approach to buying a conventional or alternative fuel vehicle. By means of the ordinal logit regression model we tested which of the research hypotheses (H1-H6) can be confirmed or rejected. The outcomes of the model are shown in Section 4.3. 
Table 1. Sociodemographic variables.

\begin{tabular}{ll}
\hline Variable & Frequencies for the Sample \\
\hline Gender & $\begin{array}{l}\text { female } 40 \% \\
\text { male } 60 \%\end{array}$ \\
\hline Age & $\mathrm{M}=36.26, \mathrm{SD}=11.15$ \\
\hline Education & $\begin{array}{l}\text { primary school } 1.0 \% \\
\text { basic vocational } 4.6 \% \\
\text { secondary vocational } 21.2 \% \\
\text { secondary education } 14.5 \% \\
\text { higher education } 56.7 \%\end{array}$ \\
\hline Material situation & $\begin{array}{l}\text { very bad or rather bad } 2.0 \% \\
\text { moderate } 33.8 \% \\
\text { rather good or very good } 63.4 \%\end{array}$ \\
\hline Place of a living & $\begin{array}{l}\text { village } 32.4 \% \\
\text { city up to } 30,000 \text { inh. } 18.6 \% \\
\text { city } 30,000 \text { to } 100,000 \text { inh. } 15.6 \% \\
\text { city } 100,000 \text { to } 500,000 \text { inh. } 10.9 \% \text { city more than } 500,000 \text { inh. } 21.8 \%\end{array}$ \\
\hline Household size & $\begin{array}{l}\mathrm{M}=3.36, \mathrm{SD}=1.54 \text { (where the integer number indicates the number of } \\
\text { family members) }\end{array}$ \\
\hline Driving license & $\mathrm{M}=2.15, \mathrm{SD}=0.97$ \\
\hline Running business & $\begin{array}{l}\mathrm{M}=0.19, \mathrm{SD}=0.40 \text { (where } 1 \text { indicates running a business and } 0 \\
\text { representing a household) }\end{array}$ \\
\hline Number of employees & $\mathrm{M}=3.9, \mathrm{SD}=12.74$ \\
\hline How long the company exists & $\mathrm{M}=8.8, \mathrm{SD}=7.13$ \\
\hline
\end{tabular}

\section{Results and Discussion}

The analysis of the data is divided into three parts. First, we present how the dependent variable, which is the willingness to purchase AFV, was obtained and measured. Second, we investigate a collection of independent variables that were chosen based on the literature review and stated research hypotheses. Finally, by means of the ordinal logit regression model, we estimate the likelihood of the willingness to buy an AFV with reference to explanatory factors.

\subsection{Analysis of Dependent Variable: AFV Preferences}

One of the key pieces of information that was obtained during the survey was knowledge about the preferences of respondents regarding the choice of the engine type in the newly purchased car. According to current market reports [30,76] we realized that most respondents would choose conventionally powered vehicles, so the question of preferences consisted of two steps. In the first step, the respondents had full freedom in choosing the engine type, and in the second step, the choice was limited to AFV. If the respondents chose a conventional vehicle in the first step, then in the second step they were asked to choose only between AFVs. However, if the respondents chose AFV in the first step, the second step was redundant. The AFV preferences of the respondents regarding the choice of the engine type were assigned values from 0 to 6 . The higher the number, the greater the respondent's readiness to buy an electric vehicle. The description of the procedure for determining the preferences of the respondents is presented in Figure 2.

The research shows that $13 \%$ of respondents indicated AFV as their first choice when buying a new car (preferences 2, 4 and 6). If the respondents had to choose between only AFV, then HEV (preferences 1 and 2) was the most popular with $45 \%$, then PHEV (preferences 3 and 4 ) -over $26 \%$ and BEV (preferences 5 and 6 ) at the level of $17 \%$. Detailed statistics for preferences are presented in Figure 3. 


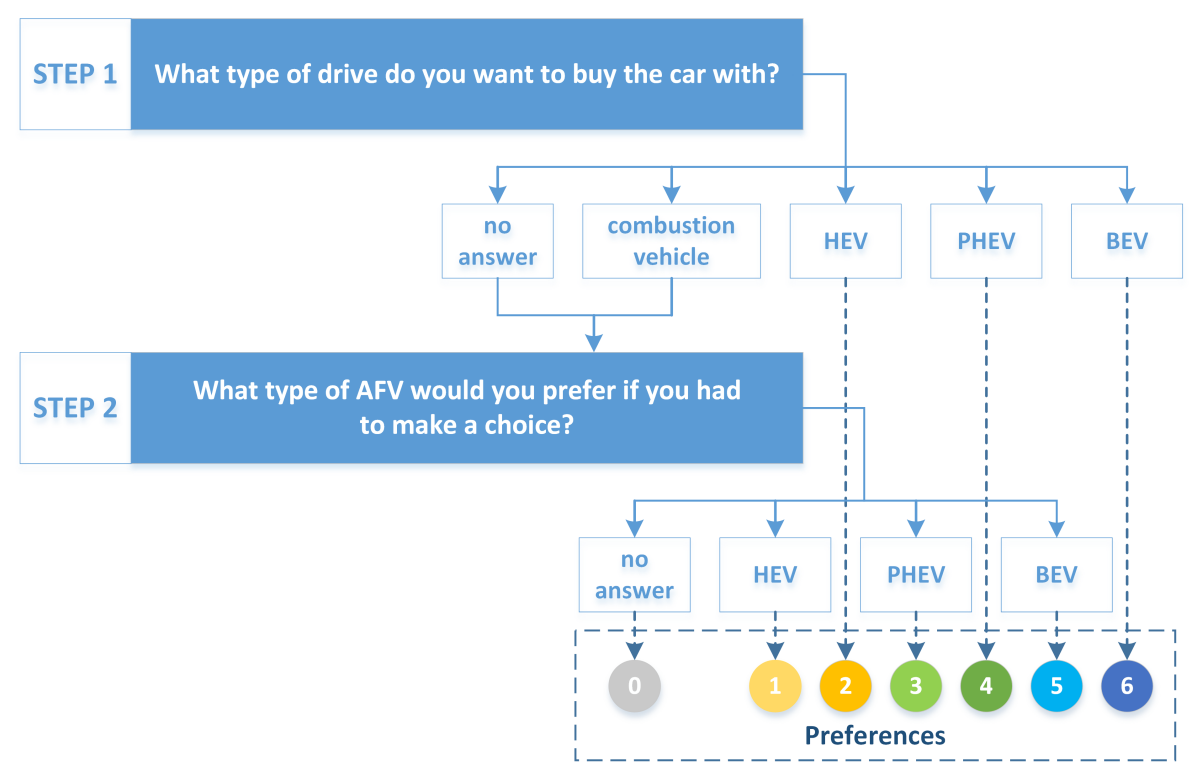

Figure 2. Procedure for determining the AFV preferences of respondents.

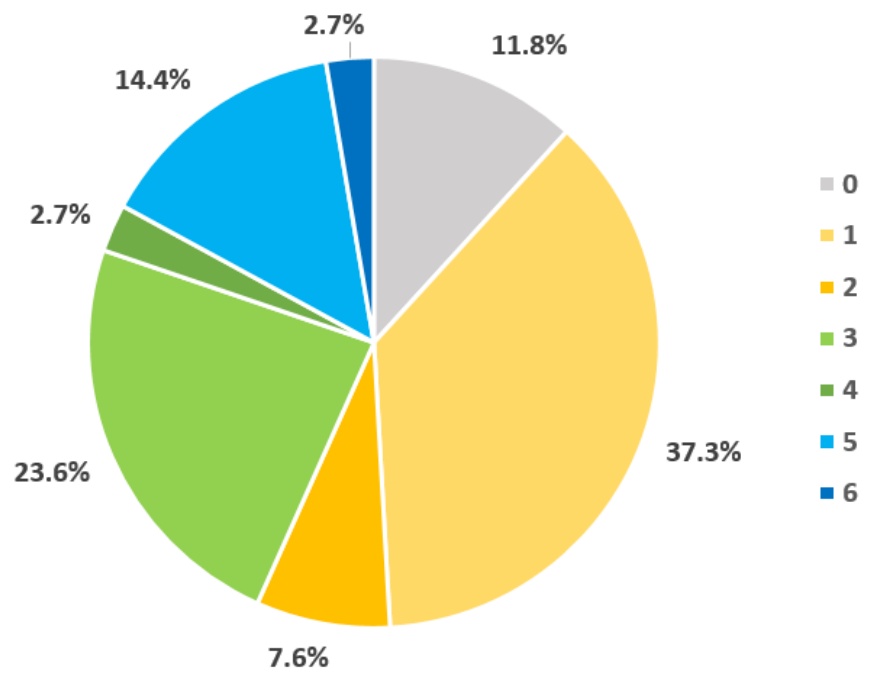

Figure 3. Respondents' AFV preferences regarding the choice of the engine type on a scale of 0 to 6 $(\mathrm{N}=1002)$.

The majority of the respondents (75\%) considered buying a car rather than leasing it $(24.3 \%)$. The mean value of the willingness to pay for such a car in case of a purchase is very low and equals to only 47,326 PLN with a standard deviation of 53,554 PLN $(1 \mathrm{PLN}=0.23$ Euro (according to the average exchange rate from the last quarter of 2020)). This is definitely not enough for any new alternative fuel vehicle. The average price of an electric car varies between 35,000 and 45,000 Euro but there are also cars with a price higher than 90,000 Euro (see [29] for more details). The mean value of the willingness to pay in the case of leasing a car is 1775 PLN with a standard deviation of 1549 PLN. Figure 4 presents the frequencies of the respondents' willingness to pay dependent on their preferred form of car acquisition (purchase by means of own or external funds or leasing). 

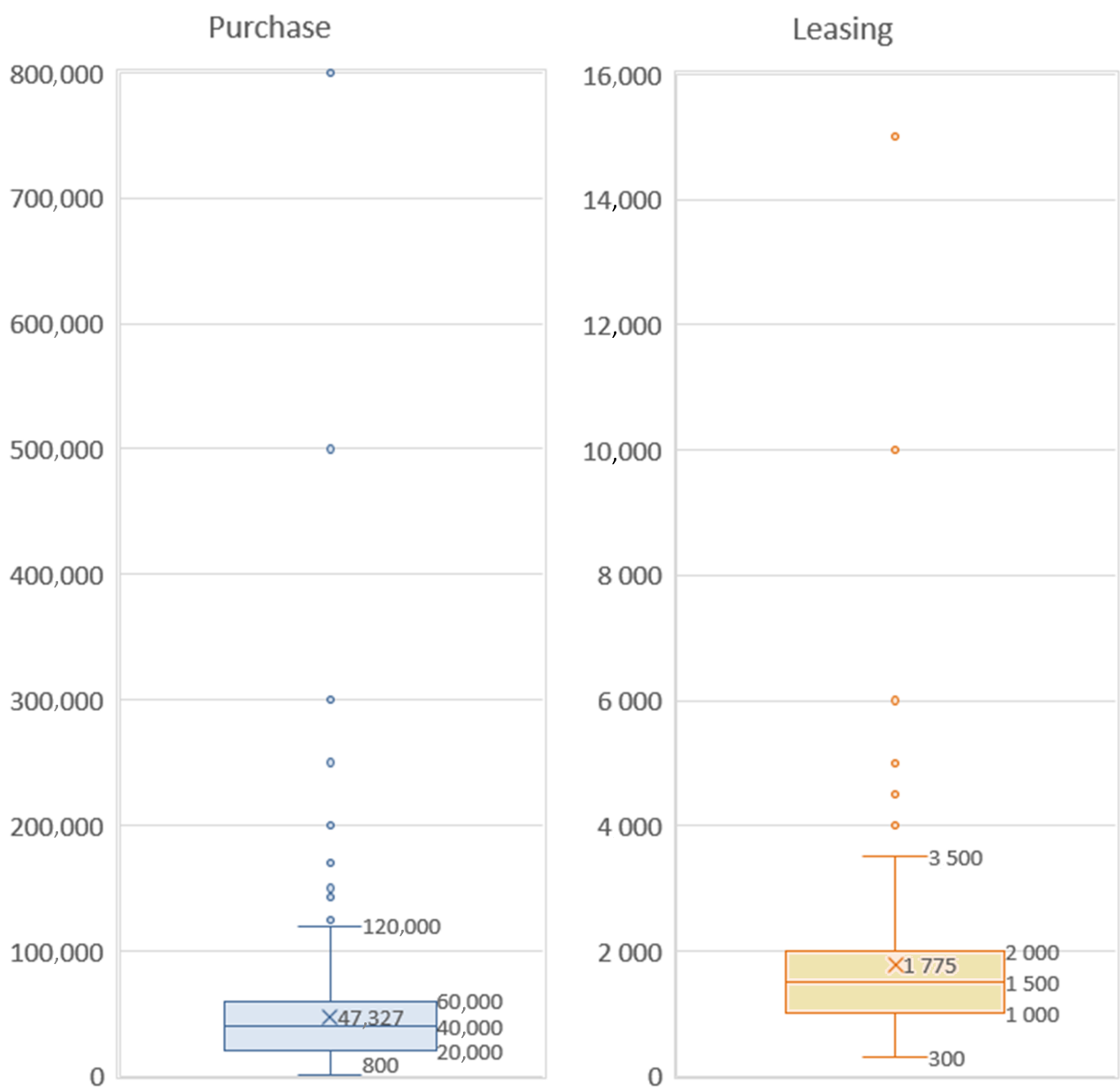

Figure 4. Frequencies of the willingness to pay (in PLN).

\subsection{Analysis of Independent Variables}

Among independent variables, we have included the environmental attitudes and behaviors, AFV recognition and knowledge, interest in automotive technologies and a set of demographic variables. The descriptive statistics of these variables have been discussed below.

\subsubsection{Environmental Attitudes and Behaviors}

Table 2 presents the questions regarding environmental attitudes and behaviors. They were inspired by NEP scale and questionnaires already used in similar surveys [43,67]. We observed that the respondents claimed to perform typical pro-environmental behaviors, such as waste segregation or turning off the lights when leaving a room, but financial support of pro-environmental institutions was rather rare. Regarding respondents' ecoattitudes, most of them are satisfied when environment and climate protection play a great role in the politics. They also believe that everybody has an impact on environment protection by one's acts and behaviors (even $81.4 \%$ strongly agree with this statement). At the same time, people are not sure whether they would like to pay higher taxes or whether the reports about the ecological crisis are exaggerated or not.

To build a construct called eco-behaviors and attitudes we have done a reliability test. As $\alpha$-Cronbach was close to 0.7 we decided to use one parameter in the further analysis. 
Table 2. Environmental attitudes and behaviors.

\begin{tabular}{lc}
\hline & Mean \\
\hline Environmental Attitudes and Behaviors: & SD \\
\hline Do you segregate waste? & 4.63 \\
Do you use reusable shopping bags? & 4.41 \\
Do you turn off the light while leaving the room? & 4.59 \\
Do you financially support any pro-environmental institutions? & 1.04 \\
Do you limit the usage of water in your household & 0.83 \\
I am satisfied with the fact that climate and environmental protection play an important role in politics & 1.19 \\
I would be willing to pay higher taxes to better protect the environment & 3.19 \\
I believe that everyone has an influence on the environment protection by one's actions & 3.03 \\
I believe that the reports about the ecological crisis are exaggerated $R$ & 1.28 \\
\hline
\end{tabular}

Note: Likert scale with following notation has been used: $5=$ strongly agree, $4=$ agree, $3=$ hard to say, $2=$ disagree, $1=$ strongly disagree;

${ }^{R}$ Reverse coding has been used to align with orientation of other questions.

\subsubsection{Interest in New Technologies}

During the study, we asked respondents if they were interested in new technologies used in the automotive industry, including for example: adaptive cruise control, driver fatigue monitoring system, control and/or checking the condition of the vehicle via a mobile phone or driving assist systems. The number of respondents interested $(\mathrm{N}=404)$ was comparable to the number of respondents not interested $(\mathrm{N}=389)$ in new technical solutions in vehicles (see Figure 5).

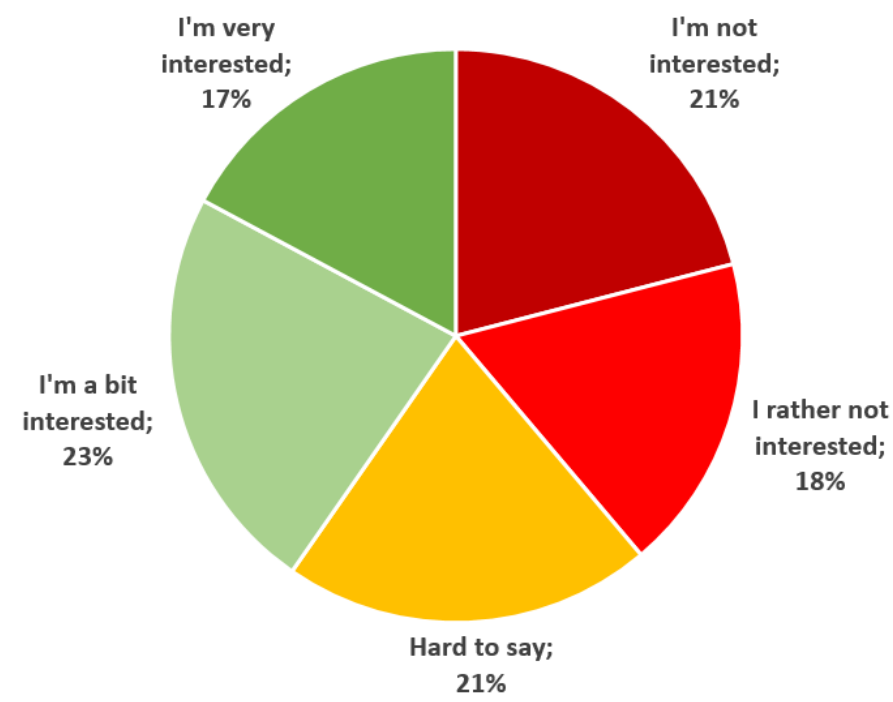

Figure 5. Interest in new technologies used in the automotive industry $(\mathrm{N}=1002)$.

\subsubsection{Knowledge Regarding Type of Fuel for AFV}

We were also interested in whether respondents can assign the type of fuel to three types of HEV, PHEV and BEV vehicles. The distribution of the answers is presented in Figure 6. Most respondents had no problems in determining the method of charging ("refueling") of BEVs. Most of the incorrect answers concerned HEVs, even though these vehicles have been available on the Polish market for over 20 years. Respondents believed that HEV vehicles need to be charged with electricity, which is in turn a feature of PHEV vehicles. Based on the answers obtained, it can be stated that the respondents did not distinguish the difference between PHEVs and classic HEVs. 


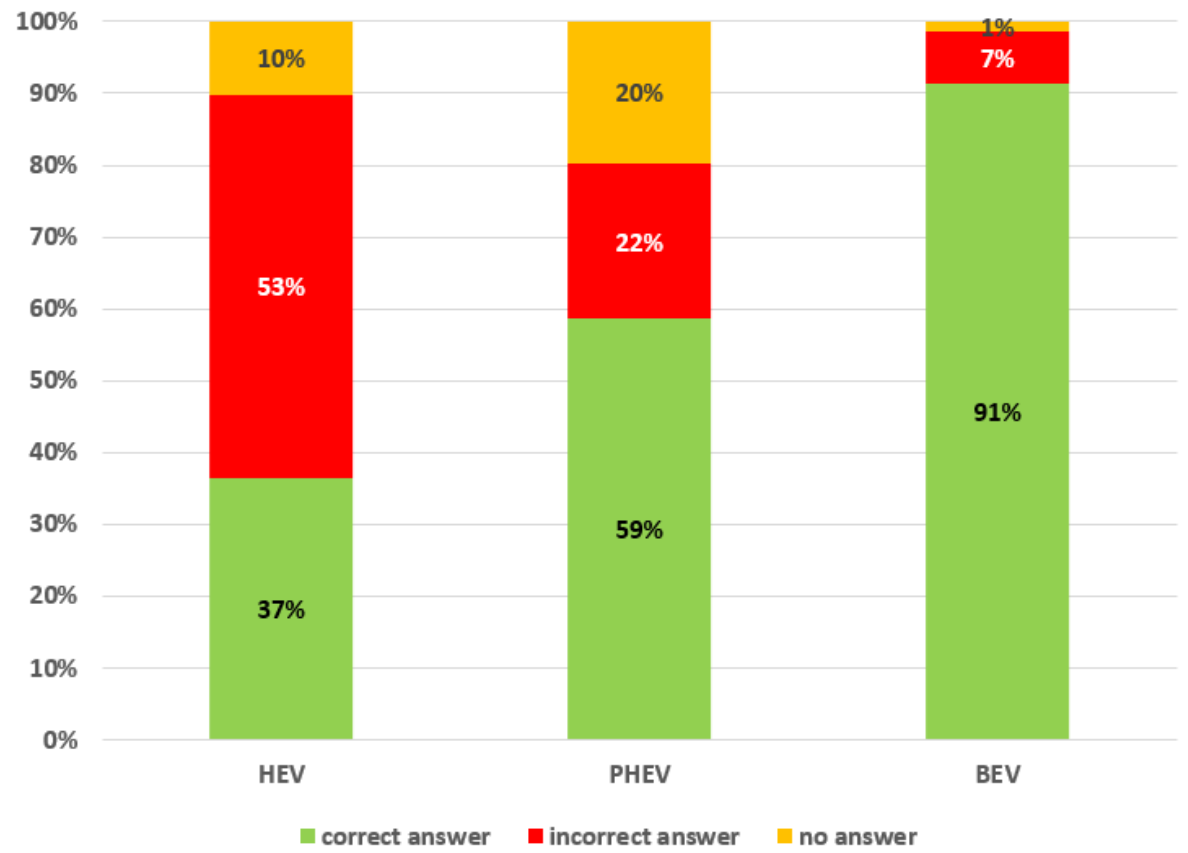

Figure 6. Frequencies of knowledge regarding type of fuels for HEV, PHEV and BEV $(\mathrm{N}=1002)$.

\subsubsection{Knowledge of AFV Brand Names}

Next, the study also explored the knowledge of brands of vehicles associated with HEV, PHEV and BEV, respectively. In the case of BEV and HEV, responses were collected from over $70 \%$ of respondents, while for PHEV only $53 \%$ of respondents were able to provide the vehicle brand. The most popular answers are summarized in Table 3. Analyzing the answers, it can be noticed that: (1) Toyota and BMW are strongly associated with alternative fuel vehicles, (2) the Tesla brand, despite the lack of representation and promotion in Poland, is highly recognizable, (3) not only premium brands are associated with the electrification of vehicles, but also the brands typical for other car segments.

Table 3. Recognition of AFV brands (the five most recognizable).

\begin{tabular}{|c|c|c|}
\hline HEV & PHEV & BEV \\
\hline 1. Toyota $60.9 \%$ & 1. Toyota $41.3 \%$. & 1. Tesla $36.8 \%$ \\
\hline 2. Lexus $10.2 \%$ & 2. BMW 7.3\% & 2. Toyota $* * 22.7 \%$ \\
\hline 3. BMW $8.0 \%$ & 3. VW $5.4 \%$ & 3. BMW $14.9 \%$ \\
\hline 4. VW 5.6\% & 4. Skoda *3.7\% & 4. Renault $14.8 \%$ \\
\hline 5. Honda 5.5\% & 5. Volvo $3.6 \%$ & 5. Nissan $14.4 \%$ \\
\hline
\end{tabular}

It should be noted that some respondents gave incorrect answers. The Toyota brand does not offer BEVs on the Polish market, but despite this fact it is strongly associated with them. In turn, the Skoda brand is a leader in car sales in Poland and at the time of the study a large advertising campaign of this brand was underway. Both factors could affect the results obtained in the study.

An important feature describing the surveyed group of respondents was the determination of how interested they are in modern technologies used in the automotive industry. The answers were distributed symmetrically (equally) $-40.4 \%$ are interested versus $38.9 \%$ not interested in new products in the automotive sector. 


\subsubsection{Sources of AFV Knowledge}

Figure 7 shows the sources of respondent knowledge about each type of AFV. The respondents drew their knowledge mainly from the mass media and were able to recognize $\mathrm{AFV}$ on the street. Much less frequently respondents talked to owners or dealers of such vehicles. Some of the respondents had empirical experience of driving an AFV vehicle, respectively HEV 39.5\%, PHEV 25.1\% and BEV 27.8\%. The very small group among the respondents were AFV owners, which reflects the share of these vehicles on the Polish market. It should be noted that the respondents more often selected an affirmative answer for HEV than for other types of vehicles (Figure 7). This fact may result from many HEVs models being available on the Polish market. For BEVs, an additional source of knowledge was included, namely official government websites. Only $10 \%$ of respondents indicated this source of knowledge. The question was related to the possibility of applying for a government subsidy for the purchase of a BEV.

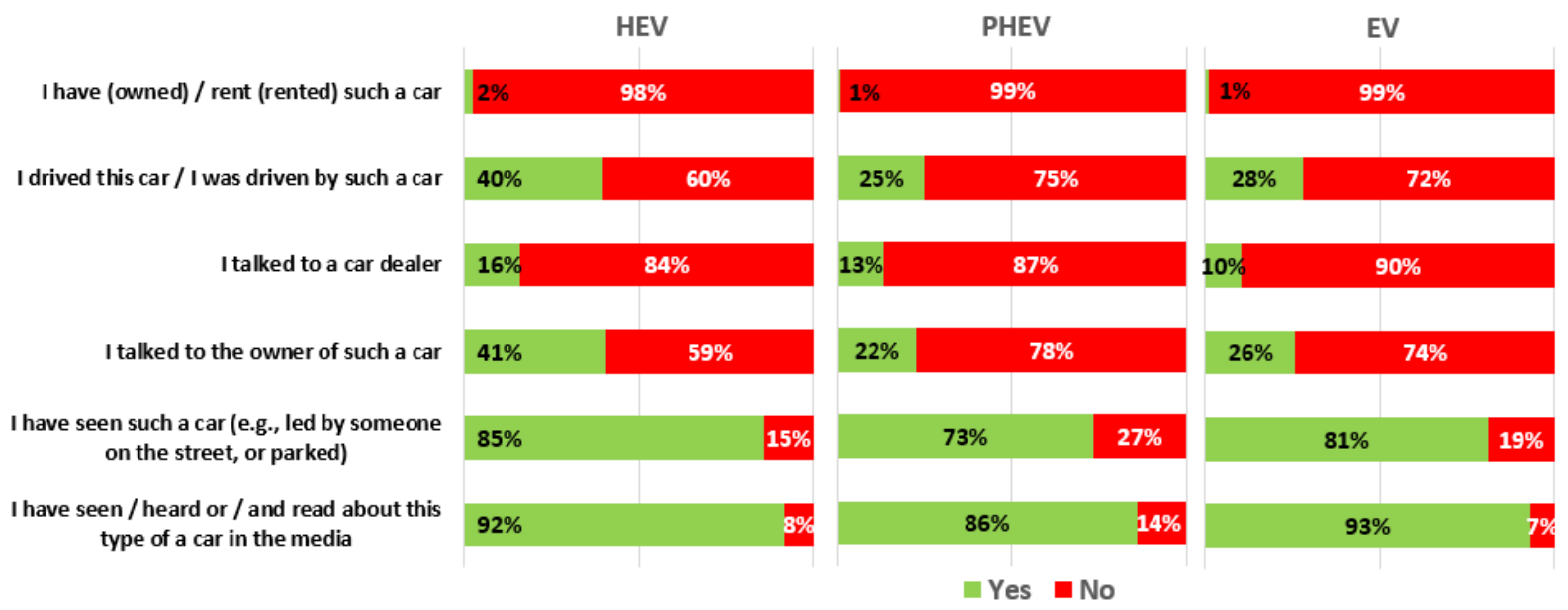

Figure 7. Sources of AFV knowledge.

4.3. Model of AFV Preferences in Terms of AFV Knowledge and Socio-Economic and Attitudinal Variables

Based on respondent willingness to buy an AFV (see Section 4.1) we construct a variable called $A F V$ preferences $\left(Y_{i}^{*}\right)$ which describes how ready respondents are to buy an electric car. In particular $\left(Y_{i}^{*}=6\right)$ means that the respondent has chosen to buy BEV in the first choice, $\left(Y_{i}^{*}=5\right)$ - the respondent has chosen to buy BEV in the second choice, $\left(Y_{i}^{*}=4\right)$-the respondent has chosen to buy PHEV in the first choice, $\left(Y_{i}^{*}=3\right)$-the respondent has chosen to buy PHEV in the second choice, $\left(Y_{i}^{*}=2\right)$-the respondent has chosen to buy HEV in the first choice, $\left(Y_{i}^{*}=1\right)$ - the respondent has chosen to buy HEV in the second choice, and $\left(Y_{i}^{*}=0\right)$ indicates the lack of answer (compare with Figure 2).

To investigate the factors influencing the preference to buy AFV we have chosen a set of explanatory factors that may have an impact. Among those factors we distinguish AFV knowledge referring to the ability to define the type of fueling and the AFV brand names. We have also included some socio-economic attributes, such as gender, age, education, place of living, running a business, as well as pro-environmental attitudes and behaviors, interest in the modern technologies and access to the charging stations. The choice of the variables was motivated by the literature review.

To analyze the $A F V$ preferences, we assumed that there is a linear relationship between the unobserved value of the $Y_{i}^{*}$ and independent variables, such as:

$$
Y_{i}^{*}=\alpha+X_{i} \beta+\varepsilon_{i}
$$

where $\alpha$ is an intercept, $X_{i}$ is a vector of independent variables excluding the constant and $\varepsilon_{i}$ is a residual. For modeling AFV preferences we used a polynominal logit model of ordered 
categories (called ordered logit model, which models cumulated probabilities). In this kind of a model, the dependent variable $\left(Y_{i}^{*}\right)$ is discreet and takes values from a countable and finite set of categories with a defined hierarchy $[77,78]$, in our case $j=0,1,2, \ldots, 6$, where $j$ represents the level of AFV preferences.

In particular we model cumulated logits, which are the logarithms of probability quotients of $i_{t h}$ respondent belonging to a category not higher than $j_{t h}\left(P_{i j}\right)$ and the opposite probability $\left(1-P_{i j}\right)$, see Equation (2):

$$
\operatorname{logit}\left(P_{i} j\right)=\ln \frac{P\left(Y_{i} \leq j\right)}{P\left(Y_{i}>j\right)}=\ln \frac{P_{i j}}{1-P_{i j}}=\beta_{0} g+\beta_{1} X_{1}+\ldots+\beta_{k} X_{k}+\varepsilon
$$

where $k$ is a set of independent variables [77].

The Table 4 presents the obtained results.

Table 4. Estimation results for the ordered logit model $(\mathrm{N}=983)$.

\begin{tabular}{lr}
\hline & Ordered Logit Model \\
\hline gender & $-0.290^{*}(0.15)$ \\
age & $0.001(0.01)$ \\
education & $-0.034(0.04)$ \\
place of living & $0.01(0.15)$ \\
running business & $0.060(0.15)$ \\
interest in technologies & $0.081^{*}(0.05)$ \\
eco-behaviors and attitudes & $0.028^{* *}(0.01)$ \\
knowledge of fueling HEV & $-0.002(0.12)$ \\
knowledge of fueling PHEV & $0.185(0.12)$ \\
knowledge of fueling BEV & $-0.125(0.21)$ \\
brand recognition & $0.146^{* *}(0.07)$ \\
access to the charging stations & $0.251^{* *}(0.11)$ \\
\hline cut1 & $-0.885(0.65)$ \\
cut2 & $1.147^{*}(0.66)$ \\
cut3 & $1.458^{* *}(0.67)$ \\
cut 4 & $2.619^{* * *}(0.66)$ \\
cut5 & $2.791^{* * *}(0.66)$ \\
cut6 & $4.787^{* * *}(0.69)$ \\
LL & -1588.85 \\
$C h i^{2}(12)$ & $302.688^{* * * *}$ \\
\hline Note: ${ }^{* * *} p<0.001, * * p<0.01,{ }^{*} p<0.05$ (two-tailed test); Standard errors in brackets. & LL stands for \\
Log-Likelihood; $C h i^{2}$ stands for Chi-square test. &
\end{tabular}

The obtained results indicate that the probability of AFV preferences (i.e., respondent willingness to buy an AFV as a future car) increases if the respondents are male, with higher interest in modern technologies used in automotive industry, good access to the charging stations, and proper brand recognition. Moreover, pro-environmental beliefs and behaviors increase the probability to prefer an AFV as a future car.

At the same time, the remaining socio-economic variables such as age, education or place of a living do not have a statistically significant influence on AFV preferences. From the stated research hypotheses, only some of them can be confirmed. Specifically, hypotheses $\mathrm{H} 2, \mathrm{H} 3, \mathrm{H} 4$ can be fully confirmed, hypotheses $\mathrm{H} 1$ and $\mathrm{H} 5$ can be partly confirmed and hypothesis $\mathrm{H} 6$ can be rejected.

\section{Conclusions and Policy Recommendations}

The automotive industry is on the verge of a technological revolution. Currently, most car companies are spending more and more financial resources on the electrification of their vehicles. Some vehicle manufacturers are already announcing that they will stop 
producing cars with internal combustion engines in the next 10 years (Volvo, JRL, MINI, Smart). However, despite significant technological advances, political support, and an expanding car dealership offering, the uptake of AFVs worldwide remains low. In the future, to develop sustainable transport and sustainable mobility, especially in cities, urgent action is needed to convince customers of their interest in the AFV market segment.

One of the most important barriers to the development of AFV is the lack of consumer awareness. Based on the research literature related to the role of knowledge and awareness in AFV recognition, we have expected the AFV knowledge to have an impact on the respondent willingness to buy AFV. The Model of AFV preferences has confirmed it partly, as proper brand recognition has occurred to increase the probability of buying AFV in the future, but at the same time knowledge about the types of fueling of AFV did not matter (Table 4). There is a clear explanation for such a finding. People interested in the purchase of AFV review the offers and are more familiar with the current brand names of the cars than the consumers not interested in buying AFV.

The research showed little interest of the respondents in purchasing BEV $(2.7 \%)$ or PHEV $(2.7 \%)$ in the first step. The respondents, having in the second step a limited choice only to AFV, did not indicate any answer (11.8\%) or indicated HEV (37.3\%) as an alternative to purchasing a combustion vehicle (Figure 3 ). It should be noted that HEVs are vehicles with the lowest degree of electrification and are the cheapest AFV. We noticed that the price of AFVs offered on the Polish market is too high for the average person interested in buying a car. This is demonstrated by the large difference between the declared willingness to pay of the respondents for a car (Figure 4) and the offer of AFV dealers [29].

The model of AFV preferences shows that the extensive infrastructure of charging points would significantly increase the willingness to buy AFV. It should therefore be noted that the development of the AFV market is strongly related to the development of the charging infrastructure.

The conducted research allows us to describe the characteristics of people interested in purchasing AFVs. Those with pro-environmental attitudes and behaviors are more interested in purchasing AFV. They see the purchase of AFV as a real impact on reducing air pollution and increasing environmental protection. In addition, people willing to buy AFV are interested in modern technologies in the automotive industry. Most of the AFVs offered on the Polish market are equipped with advanced safety systems and modern driver assistance systems, which has an impact on the interest in purchasing AFV.

We also checked the influence of socio-economic characteristics such as gender, age, education, place of a living, etc. Only gender influenced the willingness to purchase a vehicle. The AFV preference model allows for the conclusion that women are less interested in buying AFV. This confirms the rule that men buy cars more often. Research has shown that running a business does not affect the willingness to buy AVF. This may support evidence of the small range of utility AVF on the Polish market.

Summarizing the conducted research, we can state that the barriers to the development of AVF in Poland are insufficient knowledge about AVF, the purchase price of AVF, and poorly developed charging infrastructure. Our research also shows that the willingness to purchase AVF vehicles depends on pro-environmental attitudes and behavior as well as interest in new technologies.

For the tendency to buy AFV in Poland, it is first necessary to promote knowledge about AFV. We believe that exposing customers to greater experience with AFV could have a positive impact, i.e., consumers should have a possibility to have a test drive, and should be able to compare various models. Furthermore, we agree with [14] that some additional communication efforts are needed, e.g., developing an information campaign in the traditional form (leaflets, billboards, advertisements) and using social media marketing tools, organizing public events and workshops for demonstrating new technologies, increasing exposure to BEVs from fleet and car-sharing services (e.g., innogyGo or GreenGoo in Polish cities), developing the infrastructure of the charging stations, and many others. These actions are essential because many potentially interested consumers generally lack a strong 
understanding of what alternative fuel vehicles are, what benefits they offer, what models are available together with the associated incentives. Special education and marketing campaigns are needed to raise consumer awareness of AFV. Social media could be potentially useful in this process. For example some initiatives from non-profit and non-governmental organizations, such as fun clubs, which are notable for their activity and visibility on social platforms (e.g., Facebook, Twitter, Pinterest) could be used to enhance their outreach to drivers. On the other side, marketing in trade magazines and on professional platforms, such as LinkedIn, or participation at fleet events could be also a good recommendation to attract other groups of potential AFV buyers. Finally, to increase the chance of AFV adoption, reasonable selling strategies must be designed to strengthen their advantages. In particular, in a country such as Poland, the price and discount system must be adapted to the average financial purchasing power of the citizens.

\section{Future Work}

We believe that there is a further need to examine consumer knowledge and its impact on the willingness to buy AFV. In future, we are planning a longitudinal study investigating the willingness to pay for AFV in relation to consumer awareness and knowledge.

Author Contributions: Conceptualization, A.K.-P.; methodology, A.K.-P., M.K.; formal analysis, A.K.-P., M.K.; investigation, A.K.-P., M.K., J.K.; data curation, A.K.-P., M.K.; writing-original draft preparation, A.K.-P., M.K., J.K.; writing—review and editing, A.K.-P., M.K., J.K.; visualization, M.K.; supervision, A.K.-P.; funding acquisition, A.K.-P. All authors have read and agreed to the published version of the manuscript.

Funding: This research was funded by the National Science Center (NCN, Poland) by grant no. 2018/29/B/HS4/00069.

Informed Consent Statement: Informed consent was obtained from all subjects involved in the study.

Conflicts of Interest: The authors declare no conflict of interest. The funders had no role in the design of the study; in the collection, analyses, or interpretation of data; in the writing of the manuscript, or in the decision to publish the results.

\section{References}

1. Slocat Partnership. Available online: https://slocat.net/sustainable-development-goals-transport/ (accessed on 20 April 2020).

2. Chang, D.; Chen, S.; Hsu, C.; Hu, A.; Tzeng, G. Evaluation Framework for Alternative Fuel Vehicles: Perspective. Sustainability 2015, 7, 11570-11594. [CrossRef]

3. Axsen, J.; Langman, B.; Goldberg, S. Confusion of innovations: Mainstream consumer perceptions and misperceptions of electric-drive vehicles and charging programs in Canada. Energy Res. Soc. Sci. 2017, 27, 163-173. [CrossRef]

4. Long, Z.; Axsen, J.; Kormos, C. Consumers continue to be confused about electric vehicles: Comparing awareness among Canadian new car buyers in 2013 and 2017. Environ. Res. Lett. 2019, 14, 114036. [CrossRef]

5. Wang, N.; Tang, L.; Pan, H. A global comparison and assessment of incentive policy and electric vehicle promotion. Sustain. Cities Soc. 2019, 44, 597-603. [CrossRef]

6. Lopez-Carreiro, I.; Monzon, A. Evaluating sustainability and innovation of mobility patterns in Spanish cities. Analysis by size and urban typology. Sustain. Cities Soc. 2018, 38, 684-696. [CrossRef]

7. Nie, Y.; Ghamami, M.; Zockaie, A.; Xiao, F. Optimization of incentive polices for plug-in electric vehicles. Transp. Res. Part B Methodol. 2016, 84, 103-123. [CrossRef]

8. Kamiya, G.; Axsen, J.; Crawford, C. Modeling the GHG emissions intensity of plug-in electric vehicles using short term and long-term perspectives. Transp. Res. Part D Transp. Environ. 2019, 69, 209-223. [CrossRef]

9. Requia, W.; Adams, M.; Arain, A.; Koutrakis, P.; Ferguson, M. Carbon dioxide emissions of plug-in hybrid electric vehicles: A life-cycle analysis in eight Canadian cities. Renew. Sustain. Energy Rev. 2017, 78, 1390-1396. [CrossRef]

10. Peters, D.; Axsen, J.; Mallett, A. The role of environmental framing in socio-political acceptance of smart grid: The case of British Columbia, Canada. Renew. Sustain. Energy Rev. 2018, 82, 1939-1951. [CrossRef]

11. Lieven, T. Policy measures to promote electric mobility-A global perspective. Transp. Res. Part A Policy Pract. 2015, 82, 78-93. [CrossRef]

12. International Energy Agency. Global EV Outlook 2019: Towards Cross-Modal Electrification; IEA: Paris France, 2019.

13. International Energy Agency. Global EV Outlook 2020. 2020. Available online: https://webstore.iea.org/ (accessed on 12 January 2021). 
14. Jin, J.; Slowik, P. Literature Review of Electric Vehicle Consumer Awareness and Outreach Activities; Working Paper for the International Council of Clean Transportation; The International Council on Clean Transportation: Washington, DC, USA, 2017.

15. Kurani, K.; Caparello, N.; TyreeHageman, J. New Car Buyers' Valuation of Zero-Emission Vehicles: California; Plug-in Hybrid \& Electric Vehicle Center, Institute of Transportation Studies, University of California: Davis, CA, USA, 2016.

16. Browne, D.; Omahony, M.; Caulfield, B. How should barriers to alternative fuels and vehicles be classified and potential policies to promote innovative technologies be evaluated? J. Clean. Prod. 2012, 35, 140-151. [CrossRef]

17. Long, Z.; Axsen, J.; Miller, I.; Kormos, C. What does Tesla mean to car buyers? Exploring the role of automotive brand in perceptions of battery electric vehicles. Transp. Res. Part A Policy Pract. 2019, 129, 85-204. [CrossRef]

18. Larson, P.; Viafara, J.; Parsons, R.; Elias, A. Consumer attitudes about electric cars: Pricing analysis and policy implications Transp. Res. Part A Policy Pract. 2014, 69, 299-314. [CrossRef]

19. Kurani, K.; Axsen, J.; Caperello, N.; Davies, J.; Stillwater, T. Learning From Consumers: PHEV Demonstration and Consumer Education, Outreach, and Market Research Program; Working Paper Series qt9361r9h7; Institute of Transportation Studies: Davis, CA, USA, 2009.

20. Egbue, O.; Long, S. Barriers to widespread adoption of electric vehicles: An analysis of consumer attitudes and perceptions. Energy Policy 2012, 48, 717-729. [CrossRef]

21. CFA. Consumer Federation of America: Knowledge Affects Consumer Interest in EVs: New EVs Guide to Address Info Gap. 2015. Available online: http:/ / consumerfed.org (accessed on 15 April 2020).

22. Bailey, J.; Miele, A.; Axsen, J. Is awareness of public charging associated with consumer interest in plug-in electric vehicles? Transp. Res. Part D 2015, 36, 1-9. [CrossRef]

23. Bunce, L.; Harris, M.; Burgess, M. Charge up then charge out? Drivers' perceptions and experiences of electric vehicles in the UK. Transp. Res. Part A Policy Pract. 2014, 59, 278-287. [CrossRef]

24. Krupa, J.; Rizzo, D.; Eppstein, M.; Lanute, D.; Gaalema, D.; Lakkaraju, K.; Warrender, C. Analysis of a consumer survey on plug-in hybrid electric vehicles. Transp. Res. Part A 2014, 64, 14-31. [CrossRef]

25. CoxAutomative. Cox Automotive Evolution of Mobility Study: The Path to Electric Vehicle Adoption Study. 2019. Available online: https://www.coxautoinc.com/market-insights/cox-automotive-evolution-of-mobility-study-the-path-to-electricvehicle-adoption-study-released/ (accessed on 5 May 2020).

26. Polish Association of Automotive Industry. Electromobility Index: Record Year 2020 on the Polish Market Electric Cars. 2021. Available online: https://www.pzpm.org.pl/pl/Rynek-motoryzacyjny/Licznik-elektromobilnosci/Rok-2020/Grudzien-2020 (accessed on 20 February 2021).

27. The European Automobile Manufacturers' Association. European Automobile Manufacturers' Association, Alternative Fuel Vehicle Registrations. 2021. Available online: www.https://www.acea.be/statistics/tag/category/electric-and-alternativevehicle-registrations (accessed on 20 February 2021).

28. Transport\&Environment-Report. How Clean Are Electric Cars? T\&E's Analysis of Electric Car Lifecycle $\mathrm{CO}_{2}$ Emissions. Transport \& Environment. 2020. Available online: https:/ /www.transportenvironment.org/sites/te/files/T\%26E\%E2\%80\%99s \% 20EV\%20life\%20cycle\%20analysis\%20LCA.pdf (accessed on 20 December 2020).

29. Kowalska-Pyzalska, A.; Kott, J.; Kott, M. Why Polish market of alternative fuel vehicles (AFVs) is the smallest in Europe? SWOT analysis of opportunities and threats. Renew. Sustain. Energy Rev. 2020, 133, 110076. [CrossRef]

30. ACEA. European Automobile Manufacturers' Association, Making the Transition to Zero-Emission Mobility-2020 Progress Report. 2020. Available online: https:/ / www.acea.be/publications (accessed on 14 October 2020).

31. Eurostat. Road Transport Infrastructure. 2019. Available online: https:/ / ec.europa.eu/eurostat/data/ (accessed on 6 December 2020).

32. Ploetz, P.; Schneider, U.; Globisch, J.; Duetschke, E. Who will buy electric vehicles? Identifying early adopters in Germany. Transp. Res. Part A Policy Pract. 2014, 67, 96-109. [CrossRef]

33. Simsekoglu, O.; Nayum, A. Predictors of intention to buy a battery electric vehicle among conventional car drivers. Transp. Res. Part F 2019, 60, 1-10. [CrossRef]

34. Tsouros, I.; Polydoropoulou, A. Who will buy alternative fueled or automated vehicles: A modular, behavioral modeling approach. Transp. Res. Part A 2020, 132, 214-225. [CrossRef]

35. Lin, B.; Wu, W. Why people want to buy electric vehicle: An empirical study in first-tier cities of China. Energy Policy 2018, 112, 233-241. [CrossRef]

36. Ramos-Real, F.; Ramírez-Díaz, A.; Marrero, G.; Perez, Y. Willingness to pay for electric vehicles in island regions: The case of Tenerife (Canary Islands). Renew. Sustain. Energy Rev. 2018, 98, 140-149. [CrossRef]

37. Humbe, C.; Wardle, J.; Humby, R.; Poskett, H.; Nourse, C. Why Consumers Buy Electric Vehicles? Starcount Observatory Platform. 2019. Available online: www.starcount.com (accessed on 20 February 2021).

38. Bartczak, A.; Chilton, S.; Czajkowski, M.; Meyerhoff, J. Gain and losses of money in a choice experiment. The impact of financial loss aversion and risk preferences on willingness to pay to avoid renewable energy externalities. Energy Econ. 2017, 65, 326-334. [CrossRef]

39. Frank, B.; Enkawa, T.; Schvaneveldt, S.; Torrico, B. Antecedents and consequences of innate willingness to pay for innovations: Understanding motivations and consumer preferences of prospective early adopters. Technol. Forecast. Soc. Chang. 2015, 99, 252-266. [CrossRef] 
40. Ma, C.; Rogers, A.; Kragt, M.; Zhang, F.; Polyakov, M. Consumers' willingness to pay for renewable energy: A meta-regression analysis. Resour. Energy Econ. 2015, 42, 93-109. [CrossRef]

41. Sundt, S.; Rehdanz, K. Consumers' willingness to pay for green electricity: A meta-analysis of the literature. Energy Econ. 2015, 51,1-8. [CrossRef]

42. Oerlemans, L.; Chan, K.Y.; Voschenk, J. Willingness to pay for green electricity: A review of the contingent valuation literature and its source of error. Renew. Sustain. Energy Rev. 2016, 66, 875-885. [CrossRef]

43. Kowalska-Pyzalska, A. Do consumers want to pay for green electricity? A case study from Poland. Sustainability 2019, 11, 1310. [CrossRef]

44. Hackbarth, A.; Madlener, R. Consumer Preferences for Alternative Fuel Vehicles: A Discrete Choice Analysis. Transp. Res. Part Transp. Environ. 2013, 25, 5-17. [CrossRef]

45. Liao, F.; Molin, E.; van Wee, B. Consumer preferences for electric vehicles: A literature review. Transp. Rev. 2017, 37, 252-275. [CrossRef]

46. Noel, L.; Carrone, A.; Jensen, A.; Zarazua de Rubens, G.; Kester, J.; Sovacool, B. Willingness to pay for electric vehicles and vehicle-to-grid applications: A Nordic choice experiment. Energy Econ. 2019, 78, 525-534. [CrossRef]

47. Jensen, A.; Cherchi, E.; Mabit, S. On the stability of preferences and attitudes before and after experiencing an electric vehicle. Transp. Res. Part D 2013, 25, 24-32. [CrossRef]

48. Qiao, Q.; Zhao, F.; Liu, Z.; Jiang, S.; Hao, H. Comparative study on life cycle C02 emissions from the production of electric and conventional vehicles in China. Energy Procedia 2017, 105, 3584-3595. [CrossRef]

49. Yang, C. Launching strategy for electric vehicles: Lessons from China and Taiwan. Technol. Forecast. Soc. Chang. 2010, 77, 831-840. [CrossRef]

50. Buekers, J.; van Hoderbeke, M.; Bierkens, J.; Panis, L. Health and environmental benefits related to electric vehicle introduction in EU countries. Transp. Res. Part D 2014, 33, 26-38. [CrossRef]

51. Knez, M.; Obrecht, M. Policies for Promotion of Electric Vehicles and Factors Influencing Consumers' Purchasing Decisions of Low Emission Vehicles. J. Sustain. Dev. Energy Water Environ. Syst. 2017, 5, 151-162. [CrossRef]

52. de Rubens, G. Who will buy electric vehicles after early adopters? Using machine learning to identify the electric vehicle mainstream market. Energy 2019, 172, 243-254. [CrossRef]

53. Noel, L.; Zarazua de Rubens, G.; Kester, J.; Sovacool, B. Understanding the socio-technical nexus of Nordic electric vehicle (EV) barriers: A qualitative discussion of range, price, charging and knowledge. Energy Policy 2020, 138, 111292. [CrossRef]

54. Axsen, J.; Wolinetz, M. How policy can build the plug-in electric vehicle market: Insights from the Respondent-based Preference And Constraints (REPAC) model. Technol. Forecast. Soc. Chang. 2017, 117, 238-250.

55. Melton, N.; Axsen, J.; Goldberg, S. Evaluating plug-in electric vehicle policies in the context of long-term greenhouse gas reduction goals: Comparing 10 Canadian provinces using the "PEV policy report card". Energy Policy 2017, 107, 381-393. [CrossRef]

56. Kurani, K.; Tal, G. Growing PEV Markets? Notes from Recent Consumer Research. In Proceedings of the Plug-in Hybrid and Electric Vehicle Research Center of the Institute of Transportation Studies, University of California, Davis, CA, USA, 21 November 2014.

57. Singer, M. Consumer Views on Plug-In Electric Vehicles: National Benchmark Report. 2015. Available online: http://www.afdc. energy.gov/uploads/publications (accessed on 7 April 2020).

58. Karplus, V.; Patesev, S.; Reilly, J. Prospects for plug-in hybrid electric vehicles in the United States and Japan. Transp. Res. Part A 2010, 44, 620-641.

59. Sharma, K.; Manzie, C.; Bessede, M.; Crawford, R.; Brear, M. Conventional, hybrid and electric vehicles for Australia and driving conditions. Part 2: Life cycle $\mathrm{CO}_{2}$-emissions. Transp. Res. Part C 2013, 28, 63-73. [CrossRef]

60. Al-Alawi, B.; Bradley, T. Review of hybrid, plug-in hybrid and electric vehicle market modeling studies. Renew. Sustain. Energy Rev. 2013, 21, 190-203. [CrossRef]

61. Gyimesi, K.; Viswanathan, R. The Shift to Electric Vehicles: Putting Consumers in the Driver's Seat. 2011. Available online: https:/ / www.electrive.com/study-guide/the-shift-to-electric-vehicles-putting-consumers-in-the-drivers-seat/ (accessed on 20 February 2021).

62. Reiner, R.; Haas, H. Stuttgart Region-From E-Mobility Pilot Projects to Showcase Region. E-Mobility in Europe; Springer International Publishing: Berlin/Heidelberg, Germany, 2015.

63. TRB. Transportation Research Board and National Research Council. Overcoming Barriers to the Deployment of Plug-In Electric Vehicles; The National Academies Press: Washington, DC, USA, 2015; doi:10.17226/21725. [CrossRef]

64. Kannstatter, T.; Meerschiff, S. Launching an E-Carsharing System in the Polycentric Area of Ruhr. E-Mobility in Europe; Springer International Publishing: Berlin/Heidelberg, Germany, 2015.

65. Kahma, N.; Matschoss, K. The rejection of innovations? Rethinking technology diffusion and the non-use of smart energy services in Finland. Energy Resour. Soc. Sci. 2017, 34, 27-36. [CrossRef]

66. Krishnamutri, T.; Schwartz, D.; Davis, A.; Fischoff, B.; de Bruin, W.B.; Lave, L.; Wang, J. Preparing for smart grid technologies: A behavioral decision research approach to understanding consumer expectations about smart meters. Energy Policy 2012, 41, 790-797. [CrossRef] 
67. Chawla, Y.; Kowalska-Pyzalska, A. Public awareness and consumer acceptance of smart meters among Polish social media users. Energies 2019, 12, 2759. [CrossRef]

68. Chawla, Y.; Kowalska-Pyzalska, A.; Skowronska-Szmer, A. Perspectives of Smart Meters' Roll-Out in India: An Empirical Analysis of Consumers' Awareness and Preferences. Energy Policy 2020,146, 111798. [CrossRef]

69. Axsen, J.; Bailey, J.; Castro, M. Preference and lifestyle heterogeneity among potential plug-in electric vehicle buyers. Energy Econ. 2015, 50, 190-201. [CrossRef]

70. Ruggieri, R.; Ruggeri, M.; Vinci, G.; Poponi, S. Electric Mobility in a Smart City: European Overview. Energies 2021, 14, 315. [CrossRef]

71. Ingeborgrud, L.; Ryghaug, M. The role of practical, cognitive and symbolic factors in the successful implementation of battery electric vehicles in Norway. Transp. Res. Part A 2020, 130, 507-516. [CrossRef]

72. Pettifor, H.; Wilson, C.; Axsen, J.; Abrahamse, W.; Anable, J. Social influence in the global diffusion of alternative fuel vehicles-A meta-analysis. J. Transp. Geogr. 2017, 62, 247-261. [CrossRef]

73. Gnann, T.; Ploetz, P. A review of combined models for market diffusion of alternative fuel vehicles and their refueling infrastructure. Renew. Sustain. Energy Rev. 2015, 47, 783-793. [CrossRef]

74. Bjerkana, Y.; Norbech, T.; Nordtomme, M. Incentives for promoting Battery Electric Vehicle (BEV) adoption in Norway. Transp. Res. Part D Transp. Environ. 2016, 43, 169-180. [CrossRef]

75. Skowrońska-Szmer, A.; Kowalska-Pyzalska, A. Key factors of development of electromobility among microentrepreneurs: A case study from Poland. Energies 2021, 14, 764. [CrossRef]

76. PSPA. Polish Alternative Fuels Association: Barometr Nowej Mobilnosci 2020/21. 2020. Available online: https:/ /pspa.com.pl/ media/2020/11/RAPORT_Barometr_Nowej_Mobilnosci_2020.pdf (accessed on 20 December 2020).

77. Golas, Z.; Kurzawa, I. The application of ordered logit model in analysis of profitability of food industry sectors. Probl. Agric. Econ. 2014, 1, 78-96.

78. Grilli, L.; Rampichini, C. Ordered Logit Model. In Book: Encyclopedia of Quality of Life and Well-Being; Michalos, A.C., Ed.; Springer: Berlin/Heidelberg, Germany, 2014. 